\title{
Первый опыт минилапароскопической холецистэктомии
}

\author{
А. В. Малиновский, М. Н. Майоренко, Н. Н. Чернов \\ Одесский национальный медицинский университет

\section{First experience of minilaparoscopic cholecystectomy} \\ A. V. Malinovskyi, M. N. Majorenko, N. N. Chernov \\ Odessa National Medical University
}

Стандартную лапароскопическую холецистэктомию (СЛХЭ) наиболее часто выполняют в качестве миниинвазивной операции. В последнее время желчнокаменную болезнь все чаще выявляют у молодых пациенток, что обусловливает повышенные требования к косметическому результату операции. Среди разных методов минимизации доступа наиболее перспективным считают использование миниинструментов.

Минилапароскопическую холецистэктомию (МЛХЭ) выполнили пациентке 40 лет с хроническим калькулезным холециститом (длительность заболевания - около 3 лет) и множественными конкрементами диаметром от 3 до 7 мм. Приступов желчной колики в анамнезе не было. Масса тела пациентки - 65 кг (индекс массы тела 21,7 кг/ $\mathrm{M}^{2}$ ). Операцию выполняли через четыре троакара: один троакар (10 мм), введенный в области пупка, использовали для 30-градусной оптики; второй (5 мм), введенный в субксифоидальной области, использовали для основных рабочих инструментов, включая 5-миллиметровый многоразовый клипаппликатор фирмы «Lapomed» (Китай); третий и четвертый троакары были введены на 3 см ниже реберной дуги по правой среднеключичной и правой передней аксиллярной линии соответственно. Использовали 3-миллиметровые троакары и грасперы фирмы «Karl Storz» (Германия). Поскольку при работе с 5-миллиметровым клипаппликатором используются малые клипсы длиной 5 мм, что недостаточно для адекватного клипирования пузырного протока, мы адаптировали к нему средне-большие клипсы длиной 8 мм отечественного производства. Диаметр сечения позволил сохранить апертуру раскрытия клипсы в пределах 2 мм, что достаточно для наложения на неинфильтрированный пузырный проток и пузырную артерию. К данному техническому решению прибегли, поскольку в Украине еще не зарегистрированы 5-миллиметровым клипаппликаторы, при работе с которыми используются средне-большие клипсы (Ligamax, Ethicon, США).

Во время операции установили, что анатомия внепеченочных желчных протоков не изменена. Отпрепарированы элементы треугольника Кало, достигнут «критический вид безопасности». Трубчатые структуры клипи- ровали без технических трудностей с соблюдением всех правил. В ходе работы через второй троакар отметили его некоторую нестабильность по сравнению с стандартно используемым 10-миллиметровым троакаром, что потребовало дополнительной фиксации троакара ассистентом. Также с некоторыми техническими трудностями происходила тракция желчного пузыря (ЖП) миниинструментом по сравнению с стандартным 5-миллиметровым инструментом. Они были связаны как с захватом стенки ЖП, так и с самой тракцией. ЖП отделили от ложа субсерозно, без значительного кровотечения; ложе ЖП коагулировали. Затем ЖП удерживали граспером, введенным через четвертый троакар. Во второй троакар ввели 5-миллиметровый лапароскоп в направлении первого троакара, параллельно которому под визуальным контролем ввели зажим Микулича и с его помощью расширили троакарный канал, а также кожный разрез до 20 мм сразу ниже пупка. Затем ЖП граспером подвели к пупку, 10-миллиметровый троакар из него извлекли, сразу же ввели окончатый зажим, которым до потери пневмоперитонеума под визуальным контролем захватили ЖП и извлекли наружу. Апоневроз в области пупка ушили Z-образным нерассасывающимся швом. Дренаж в ложе ЖП не устанавливали. Кожные раны ушили внутрикожным косметическим швом нитью Vicril Rapid 3-0 (Ethicon). Операция длилась 90 мин.

Послеоперационный период протекал без осложнений. Пациентка отмечала менее выраженный болевой синдром, чем после СЛХЭ. На момент выписки пациентки к концу 2-х суток болевой синдром исчез. При контрольном осмотре через 1 нед состояние кожных ран удовлетворительное, жалоб нет. Пациентка оценила косметический эффект операции как отличный.

Для минимизации лапароскопического доступа при холецистэктомии предложено несколько вариантов. В 2006-2007 гг. были выполнены первые трансвагинальные и трансгастральные холецистәктомии, положившие начало технологии NOTES (Natural Orifice Transluminal Endoscopic Surgery - эндоскопическая хирургия через естественные отверстия) [1]. Из-за ряда технических сложностей это направление практически не получило 
развития. В 2009 - 2014 гг. взамен NOTES активно стали развивать SILS (Single Incision Laparoscopic Surgery - лапароскопическая однопортовая хирургия). Количество этих операций также стремительно уменьшается. Однако с появлением 2- и 3-миллиметровых троакаров, так называемых минитроакаров, и соответствующих инструментов на первое место вышли минилапароскопические операции [2].

Основные недостатки однопортовых вмешательств: необходимость использования специального одноразового SILS-порта, специальных изогнутых или изгибаемых инструментов, желательно специально изгибаемой оптики, но самое главное - неадекватная тракция ЖП, постоянный «конфликт инструментов» и техническое неудобство операции. В итоге оказалось, что SILS не имеет преимуществ по сравнению с СЛХЭ, более того, наметилась тенденция к увеличению риска развития троакарных грыж и сером в области пупка. Ряд методик, призванных компенсировать описанные технические неудобства, не стали популярными [2].

МЛХЭ сохраняет все преимущества СЛХЭ и не связана с риском интраоперационных осложнений, включая повреждение внепеченочных желчных протоков, которое возможно при SILS [3]. В Кокрановском обзоре преимуществ МЛХЭ по сравнению с СЛХЭ не отмечено [4]. Однако по данным последних проспективных рандомизированных исследований МЛХЭ характеризуют как операцию с достоверно менее выраженным болевым синдромом, лучшим косметическим результатом, меньшей продолжительностью реабилитации по сравнению с СЛХЭ, причем не повышается достоверно длительность операции, а лучший косметический эффект наблюдали даже через 3 мес после операции [5, 6]. К недостаткам МЛХЭ можно отнести ограниченную возможность ее использования, когда приступ острого холецистита купирован, у тучных пациентов, из-за прочих объективных технических неудобств, связанных в первую очередь с миниграсперами, которыми не возможно надежно захватить утолщенную стенку ЖП и обеспечить достаточную тракцию в этих условиях [7], о чем свидетельствует наш первый опыт. Также мы обратили внимание на нестабильность 5-миллиметрового троакара, введенного в субксифоидальной области, что затрудняло привычную диссекцию треугольника Кало. Безусловно, именно этот штатный клипаппликатор Ligamax (Ethicon, США) лучше использовать при рутинном выполнении МЛХЭ. Поскольку такие клипаппликаторы не зарегистрированы в Украине, мы использовали адаптированные средне-большие клипсы с многоразовым 5-миллиметровым клипаппликатором. Использование многоразового клипаппликатор позволяет значительно сократить расходы на операцию. Естественно, не- обходимо большее количество сравнительных исследований, включая проспективные рандомизированные, для того, чтобы показать преимущества МЛХЭ по сравнению с СЛХЭ и четко определить показания к ее выполнению. В настоящее время МЛХЭ выполняет ограниченное число специалистов у молодых пациенток с хроническим калькулезным холециститом, желающих иметь идеальный косметический эффект, когда нет технических неудобств. Если возникают технические неудобства, переход к СЛХЭ не представляет трудности.

\section{Выводы}

1. Первый опыт МХЛЭ с использованием многоразового 5-миллиметрового клипаппликатора с адаптированными клипсами и 3-миллиметровых троакаров и грасперов показал надежность методики без начительных технических трудностей по сравнению с выполнением СЛХЭ.

2. После МЛХЭ выраженность болевого синдрома значительно меньше и значительно лучше косметический результат по сравнению с СХЛЭ.

3. Необходимо дальнейшее накопление материала и сравнение МЛХЭ с СЛХЭ для определения возможностей и ограничений данной методики.

\section{References}

1. Markar SR, Karthikesalingam A, Thrumurthy S, Muirhead L, Kinross J, Paraskeva P. Single-incision laparoscopic surgery (SILS) vs. conventional multiport cholecystectomy: systematic review and meta-analysis. Surg Endosc. 2012 May;26(5):1205-13. doi: 10.1007/s00464-011-2051-0.

2. Tan X, Wang G, Tang Y, Bai J, Tao K, Ye L. Minilaparoscopic versus single incision cholecystectomy for the treatment of cholecystolithiasis: a meta-analysis and systematic review. BMC Surg. 2017 Aug 22;17(1):91. doi: 10.1186/s12893-017-0287-x

3. de Carvalho LF, Fierens K, Kint M. Minilaparoscopic versus conventional laparoscopic cholecystectomy: a randomized controlled trial. J Laparoendosc Adv Surg Tech A. 2013 Feb;23(2):109-16. doi: 10.1089/ lap.2012.0349.

4. Gurusamy KS, Vaughan J, Ramamoorthy R, Fusai G, Davidson BR. Miniports versus standard ports for laparoscopic cholecystectomy. Cochrane Database Syst Rev. 2013 Aug 1;(8).CD006804. doi: 10.1002/14651858. CD006804.pub3.

5. Alhashemi M, Almahroos M, Fiore JF Jr, Kaneva P, Gutierrez JM, Neville A, Vassiliou MC, Fried GM, Feldman LS. Impact of miniport laparoscopic cholecystectomy versus standard port laparoscopic cholecystectomy on recovery of physical activity: a randomized trial. Surg Endosc. 2017 May;31(5):2299-309. doi: 10.1007/s00464-016-5232-z.

6. Novitsky YW, Kercher KW, Czerniach DR, Kaban GK, Khera S, Gallagher-Dorval KA, et al. Advantages of mini-laparoscopic vs conventional laparoscopic cholecystectomy: results of a prospective randomized trial. Arch Surg. 2005 Dec;140(12):1178-83. doi: 10.1001/archsurg.140.12.1178

7. Dammaro C, Tranchart H, Gaillard M, Debelmas A, Ferretti S, Lainas $\mathrm{P}$, et al. Routine mini-laparoscopic cholecystectomy: Outcome in 200 patients. J Visc Surg. 2017 Apr;154(2):73-7. doi: 10.1016/j.jviscsurg.2016.08.001. 